\title{
Short-term high-fat diet affects macrophages inflammatory response, early signs of a long-term problem
}

\author{
Ed Wilson Santos ${ }^{1 *}$, Dalila Cunha Oliveira ${ }^{1}$, Araceli Hastreiter ${ }^{1}$, Graziela Batista Silva ${ }^{1}$, Jackeline \\ Soares de Oliveira Beltran', Marcelo Macedo Rogero ${ }^{2}$, Ricardo Ambrósio Fock ${ }^{1}$, Primavera Borelli ${ }^{1}$
}

\author{
${ }^{1}$ Department of Clinical and Toxicological Analyses, School of Pharmaceutical Sciences, University of Sao Paulo, Sao Paulo, \\ SP, Brazil, ${ }^{2}$ Department of Nutrition, School of Public Health, University of Sao Paulo, SP, Brazil
}

\begin{abstract}
Obesity is a chronic inflammatory disease that affects millions of people worldwide. Most studies observe the effects of a high-fat diet (HFD) in 10-12 weeks. This work investigated the effects induced by a HFD administered for 6 weeks on the nutritional status of mice and some aspects of the inflammatory response in mouse peritoneal macrophages. Male Swiss Webster mice, 2-3 months of age, were fed a control diet or HFD for 6 weeks. After this period, the mice were euthanized, and peritoneal macrophages were collected for immunoassays and assessment of biochemical parameters. A HFD was associated with increased cholesterol, insulin resistance, C-reactive protein (CRP), leptin, and serum resistin levels. Lipopolysaccharide (LPS)- stimulated adipocyte cultures of animals subjected to a HFD showed increased production of proinflammatory cytokines such as tumor necrosis factor alpha (TNF- $\alpha$ ), interleukin-1 (IL-1), and interleukin-6 (IL-6). However, peritoneal macrophages of the HFD group showed no changes in the levels of these cytokines. LPS-stimulated peritoneal macrophages from HFD-treated animals showed a reduction in mRNA expression of TNF- $\alpha$ and IL- 6 , as well as a decrease in expression of the transcription factor nuclear factor-kappa B (NF-kB). In conclusion, HFD treatment for 6 weeks induces similar signs to metabolic syndrome and decreases the capacity of peritoneal macrophages to develop an appropriate inflammatory response to a bacterial component.
\end{abstract}

Keywords: High-fat diet/study. Mice. Macrophages. Metabolic syndrome. NF-kB.

\section{INTRODUCTION}

Obesity can be simply defined as a disease characterized by an excessive increase in body fat as a result of a positive energy balance, which affects the individual's health and is associated with a considerable loss of quality of life and reduced life expectancy (FAO, 2013).

A high-fat diet (HFD) is considered a major risk factor for cancer with the involvement of dysregulated oxidative stress. It is well established that metabolic inflammation disrupts cellular metabolism and impairs insulin signaling in metabolically active tissues. Is believed to be a major contributor to the development of insulin resistance, which is an early event and can lead to

\footnotetext{
*Correspondence: E. W. Santos. Laboratório de Hematologia Experimental, Departamento de Análises Clínicas e Toxicológicas, Faculdade de Ciências Farmacêuticas, Universidade de São Paulo. Avenida Lineu Prestes, 580 Bloco 17, 05508-900 - São Paulo - SP, Brazil. E-mail: ed.wilson@usp.br
}

type 2 diabetes (Saaman, 2011). However, how early a HFD can influence inflammation is as yet ill-defined (Van Der Heijden et al., 2015; Vykhovanets et al., 2011).

The intake of a diet rich in lipids is associated with increased plasma leptin levels and adipocytes, the latter being the major producers of leptin as well as other mediators, especially inflammatory ones such as tumor necrosis factor alpha (TNF- $\alpha$ ), interleukin-1 beta (IL$1 \beta$ ), and interleukin-6 (IL-6) (Schaffler, Scholmerich, Salzberger, 2007).

Leptin also acts on the immune system, stimulating the production and migration of white blood cells in the bone marrow. It also increases the production of proinflammatory cytokines, such as TNF- $\alpha$ and IL-6, and the adhesion and phagocytosis of macrophages and stimulates the proliferation of T lymphocytes (Silveira et al., 2009). Recent studies have shown that obesity decreased the blood flow in adipose tissue, causing hypoxia, which initiates a proinflammatory process (Zeyda, Stulnig, 2007). 
Macrophages play an essential role in the body due to the wide variety of physiological and pathological processes in which they operate. They are essential in the immune response, acting in phagocytosis, the secretion of cytokines, and antigen presentation, as well as the production of reactive oxygen and nitrogen species (Patel, Buras, Balasubramanyam, 2013).

Lipopolysaccharide (LPS) is present in the outer cell membrane of gram-negative bacteria and some highly toxic molecules from gram-positive bacteria. This endotoxin could trigger intracellular signaling pathways through cell membrane receptors, which are known as Toll-like receptor 4, triggering the activation of nuclear factor-kappa B (NF-kB) (Amar et al., 2007).

Obesity is associated with chronic low-grade inflammation. Recent findings have established an association between obesity and immune dysfunction. However, most studies investigating the effects of obesity induced by a HFD were conducted in long-term animal models (Wellen, Hotamisligil, 2003; Van Der Heijden et al., 2015; Vykhovanets et al., 2011).

Since the data in the literature describe obesogenic effects of a HFD once the metabolic syndrome is already present, we focused on determining early effects of a HFD on biochemical parameters and the macrophage inflammatory response.

\section{MATERIAL AND METHODS}

\section{Animals and diets}

Male Swiss Webster mice, 2-3 months old and outbred, were obtained from the Faculty of Pharmaceutical Sciences, University of São Paulo. This study was approved by the Ethics Committee on the Use of Animals of the University of São Paulo (Protocol: $\mathrm{CEUA} / \mathrm{FCF} / 366$ ). The animals were housed individually in cages under similar environmental conditions, with a clear light/dark cycle of $12 / 12 \mathrm{~h}$, temperature of $22 \pm 2{ }^{\circ} \mathrm{C}$ and relative humidity of $55 \pm 10 \%$. After acclimatization to the diet based on the American Institute of Nutrition recommendations for the adult rodent (AIN-93M) (Reeves, Nielsen, Fahey, 1993) for 10 days, mice were randomly assigned to the high-fat $(\mathrm{H})$ group or the control (C) group. For 6 weeks, the $\mathrm{C}$ group received the AIN-93M diet (total energy, 75.8\% carbohydrates, 9.3\% fat, and $14.9 \%$ protein), whereas the $\mathrm{H}$ group received an AIN-93M-based diet enriched with lard (total energy, $24.2 \%$ carbohydrates, $60.9 \%$ fat, and $14.9 \%$ protein), as shown in Table I. In previous studies (Borges et al., 2013; Santos et al., 2016a), we observed that mice and rats in the $\mathrm{H}$ group consumed approximately $30 \%$ less diet than the $\mathrm{C}$ group. However, given the higher energy density of the $\mathrm{H}(23.2 \mathrm{~kJ} / \mathrm{g})$ compared with the $\mathrm{C}$ diet $(16.7 \mathrm{~kJ} / \mathrm{g})$, the daily energy intake did not differ between the groups. During the experiment, body weight and feed consumption were evaluated every 48 hours.

TABLE I - Experimental diet composition

\begin{tabular}{lcc}
\hline \multirow{2}{*}{ Ingredients } & Control diet $^{\mathbf{1}}$ & High-fat Diet \\
\cline { 2 - 3 } & \multicolumn{2}{c}{$\mathbf{g} / \mathbf{1} \mathbf{1 0 0 0}$ kcal } \\
\hline Cornstarch & 155.40 & 29.65 \\
Sucrose & 25.04 & 25.04 \\
Casein & 35.05 & 35.05 \\
Soybean oil & 10.01 & 10.01 \\
Lard & ----- & 55.44 \\
Cellulose & 12.52 & 12.52 \\
Mineral mix & 8.76 & 8.76 \\
Vitamin mix & 2.50 & 2.50 \\
L-cystine & 0.45 & 0.45 \\
Choline bitartrate & 0.63 & 0.63 \\
Tertbutylhydroquinone & 0.002 & 0.007 \\
\hline
\end{tabular}

${ }^{1}$ According to AIN-93M

\section{Blood analyses}

The animals were subjected to 8 hours of fasting. Then, whole blood was obtained by puncturing the axillary plexus of mice anesthetized with xylazine $(16 \mathrm{mg} / \mathrm{kg})$ and ketamine $(120 \mathrm{mg} / \mathrm{kg})$. Blood samples containing EDTA (Sigma-Aldrich ${ }^{\circledR}$, USA) as an anticoagulant were used to perform a hemogram. The evaluation was performed on ABX Micros ABC Vet equipment (Horiba ${ }^{\circledR}$, France). Morphological and leukocyte differentiation analyses were conducted on blood smears stained using the standard May-Grünwald-Giemsa (Sigma-Aldrich ${ }^{\circledR}$, USA) technique.

Serum samples of cholesterol, triglycerides, total protein and albumin were quantified using the respective kits (Labtest ${ }^{\circledR}$, Brazil). The samples were processed in duplicate. The serum concentrations of insulin, leptin, resistin, adiponectin, IL-6, TNF- $\alpha$ and C-reactive protein were quantified using the Lincoplex ${ }^{\circledR}$ kit (Linco Research Inc. ${ }^{\circledR}$, USA) following the manufacturer's instructions.

The glucose measurement was performed with blood from the tail of the previously anesthetized animals and determined using an Accu-Check Advantage glucometer (Roche ${ }^{\circledR}$, Switzerland). The homoeostasis model assessment-insulin resistance (HOMA-IR) index was 
calculated using the following formula: (fasting serum insulin $(\mathrm{mU} / \mathrm{ml}) \mathrm{X}$ fasting plasma glucose $(\mathrm{mmol} / \mathrm{l}) / 22.5)$.

\section{Measurement of visceral fat and Lee index}

Subsequent to blood collection and euthanasia, the retroperitoneal and periepididymal adipose pads were dissected and immediately weighed. We used the Lee index (Rogers, Webb, 1980), a factor that measures the body mass index (BMI) of mice, with the following link: [weight $\left(\mathrm{g}^{0.33}\right) /$ naso-anal measured $(\mathrm{mm})$ ]. These values are equivalent to body mass index (BMI) of human value and may characterize the change in mass of mice after the induction of obesity.

\section{Histological Assessment}

The peri-epididymal fat was collected and fixed in Carnoy for 1 hour with stirring. Then it was placed in $70 \%$ alcohol until the histological sections were made. Tissues were processed in paraffin and slices (about 5 microns) were stained with hematoxylin-eosin and photographed under a light microscope (Altintas et al., 2011).

\section{Phenotypic characterization of peritoneal cells}

Phenotypic characterization of peritoneal cells was performed by flow cytometry. Aliquots of $1 \times 10^{5}$ cells $/ \mathrm{ml}$ of cell suspension from the sample of peritoneal lavage cells, suspended in McCoy medium (Cultilab $\AA$, Brazil), $\mathrm{pH}$ 7.4. Antibodies were added and incubated for 30 minutes with $2 \mu \mathrm{L}$ antibody APC-F4/80 (Cat 113006, Lot \# b146514 Biolegend ${ }^{\circledR}$ ) and/or $2 \mu$ L FITC-CD11b antibody (Cat 11-0112-82, Lot \# E033743 eBioscience), stirred, and protected from light. The acquisition was made on FACSCanto II (Becton Dickson ${ }^{\circledR}$, USA) acquiring 10,000 events analyzed and compensated by the software FLOW JO ${ }^{\circledR} 7.6$ (TreeStar ${ }^{\circledR}$, USA).

\section{Cell culture}

Peritoneal macrophages were obtained by washing the peritoneal cavity with $5 \mathrm{~mL}$ of sterile and pyrogenfree McCoy culture medium ( $\mathrm{pH}$ 7.4) supplemented with $10 \%$ fetal bovine serum, $2 \mathrm{mmol} / \mathrm{L}$ glutamine, $100 \mathrm{U} /$ $\mathrm{mL}$ penicillin and $100 \mathrm{mg} / \mathrm{mL}$ streptomycin $\left(\mathrm{Cultilab}^{\circledR}\right.$, Campinas, Brazil). Cells were spun down (1500 rpm for $10 \mathrm{~min}$ at $4{ }^{\circ} \mathrm{C}$ ) and resuspended twice in McCoy culture medium. Cell viability was determined by Trypan blue exclusion. Cultures were done with the collected cells and we carried out the immunophenotypic characterization of macrophages. Cultures rich in macrophages were obtained by incubating $1 \times 10^{6}$ cells $/ \mathrm{mL}$ in 24 polystyrene culture plates for $2 \mathrm{~h}$ at $37^{\circ} \mathrm{C}$ in a $5 \% \mathrm{CO}_{2}$ humidified air environment. Non-adherent cells were removed by three vigorous washings with McCoy medium. Macrophages were incubated with $1 \mathrm{mg} / \mathrm{mL}$ of LPS (Escherichia coli, serotype 055:B5, Sigma Chemical Company ${ }^{\circledR}$, MO, USA) (Fock et al., 2007). After $1 \mathrm{~h}$ of incubation with LPS, the cells were used to assess NF-kB phosphorylation and expression through western blotting. After $1 \mathrm{~h}$ of incubation with LPS, the supernatant was used to determine IL-1 $\beta$, IL- 6 and TNF- $\alpha$ concentrations in the culture. The entire procedure was executed under aseptic conditions and all materials used were sterile and pyrogen-free. Total cells were determined using a Neubauer chamber and the presence of different cell types were quantified on cytocentrifuge smears stained using the standard MayGrünwald-Giemsa solutions.

\section{Adipocyte culture}

The peri-epididymal adipose tissue harvested was immersed in $3 \mathrm{ml}$ of DMEM culture medium. The adipose tissue was sectioned into small pieces to provide a homogeneous consistency, increasing the contact area with the medium. After fragmentation, the tissue was transferred to a collector pipe, and $2.5 \mathrm{~mL}$ medium was added for every $1 \mathrm{~g}$ of adipose tissue. The culture was placed in a $37^{\circ} \mathrm{C}$ water bath under gentle shaking for 30 minutes. After this incubation, the cells were transferred to a $50-\mathrm{ml}$ tube by filtration through a fine mesh. Then, medium was added to a final volume of $25 \mathrm{ml}$. The sample was centrifuged at 400 $g$ for 30 seconds. After centrifugation, the adipocytes were on the surface, and the stromal cells were in the sediment. The sediment was then carefully aspirated. If necessary, the procedure was repeated for better washing of adipocytes (Peres, Curi, 2005).

Mature adipocytes float easily, and gentle swirling is required during the dividing process to obtain an equal number of cells per plate or tube. The tubes were placed in a cell culture incubator for 2 hours (Carswell, Fee, Fried, 2012).

\section{Bone marrow cellularity}

Femurs of the $\mathrm{C}$ and $\mathrm{H}$ mice were removed under aseptic conditions, and the bone marrow cells were flushed from them using Iscove's medium supplemented with $10 \%$ fetal horse serum (Vitrocell ${ }^{\mathrm{TM}}$, Campinas, SP, Brazil). The cells were washed by addition of complete medium, centrifugation for 10 minutes at $1200 \mathrm{rpm}$ at $24{ }^{\circ} \mathrm{C}$, and 
removal of the the supernatant. An aliquot of the cells in suspension obtained from the bone marrow was diluted in Turk's liquid for nucleated cell counting in a Neubauer chamber.

\section{Cellular identification by immunohistochemistry}

Cells were washed twice with PBS for 5 minutes and incubated with PBS solution containing horse serum at a 1:100 dilution to block non-specific binding. After 30 minutes of incubation in a dark, wet chamber, the excess blocking solution was removed, and the cells were incubated with diluted primary antibody in $0.02 \mathrm{M}$ PBS solution, $\mathrm{pH} 7.2$ with $1 \%$ sodium azide and $1 \%$ bovine albumin overnight (16 hours) in a darkroom at $4{ }^{\circ} \mathrm{C}$. After this period, the cells were washed twice with PBS for 5 minutes to be incubated with the FITC-conjugated secondary antibody F4/80 at a dilution of 1:100 for 45 minutes in a humid chamber at room temperature. After these procedures, the cells were observed under a Nikon 80i fluorescence microscope.

\section{Cytokines in culture supernatants}

Cytokine analysis was performed on samples of culture supernatant of peritoneal cells or peri-epididymal adipose tissue obtained after 2 hours of cultivation. The concentrations of TNF- $\alpha$, IL- $1 \beta$, and IL- 6 were determined by means of an ELISA-type immunoassay, using a Quantikine ${ }^{\circledR}$ kit (R\&D System ${ }^{\circledR}$, MN, USA) according to the methodology described by the manufacturer.

\section{Western blot analysis of NF-kB and p-NF-Kb}

To determine the protein levels of NF $\kappa \mathrm{B}$ and phosphorylated NFKB, western blot analysis of peritoneal macrophages was performed after $1 \mathrm{~h}$ of incubation in the presence or absence of LPS stimulation. The cells were washed with PBS three times and lysed with RIPA buffer $(0.1 \%$ SDS, $1 \%$ Igepal CA-630, $1 \%$ sodium deoxycholate, $10 \mathrm{mM}$ Tris- $\mathrm{HCl}$ (pH 7.5), $150 \mathrm{mM} \mathrm{NaCl}$, $2 \mu \mathrm{g} / \mathrm{mL}$ aprotinin, $1 \mu \mathrm{g} / \mathrm{mL}$ leupeptin, $100 \mu \mathrm{g} / \mathrm{mL}$ PMSF, and $0.5 \mathrm{mM}$ EDTA). To inhibit the activity of proteases and phosphatases, a protease and phosphatase inhibitor cocktail was added (Sigma Chemical Co., St. Louis, MO, USA). After $15 \mathrm{~min}$ of centrifugation at 14.000 rpm and $4^{\circ} \mathrm{C}$, the supernatant was collected, mixed with 5x Laemmli buffer (1 M Tris $\mathrm{HCl}(\mathrm{pH} 6.8), 10 \%$ 2-mercaptoethanol, $10 \%$ SDS, $50 \%$ glycerol, and $0.01 \%$ bromophenol blue) and boiled for $5 \mathrm{~min}$. The protein content of the cell homogenates was determined using a
BCA Protein Assay Kit (Pierce Biotechnology ${ }^{\circledR}$, USA), and equal amounts of protein $(10 \mu \mathrm{g}$ per well) were placed on $10 \%$ SDS-polyacrylamide mini-gels and transferred to Immobilon polyvinylidene difluoride membranes (Millipore Corporation ${ }^{\circledR}$, USA). After incubation with the antibodies against NFкB $(1: 1000$, SC-372; Santa Cruz Biotechnology $^{\circledR}$, USA), or pNF KB (5:1000, SC-33039; Santa Cruz Biotechnology ${ }^{\circledR}$, USA), at room temperature overnight, the membranes were incubated with the secondary antibody $(1: 5000)$ conjugated to horseradish peroxidase (Cat. 7074S; Cell Signaling, Inc., USA) for $1 \mathrm{~h}$. After three washes with TBST, the immunoreactive bands were visualized using the ECL detection system (Amersham ECL ${ }^{\text {TM }}$ Advance Western Blotting Detection $\mathrm{Kit}^{\mathbb{R}}$, USA). To standardize and quantify the immunoblots, we used a digital detection system (ImageQuant ${ }^{\mathrm{TM}} 400$ version 1.0.0, Amersham Biosciences ${ }^{\circledR}$, USA). The results were expressed in relation to the intensity of $\beta$-actin (1:40,000 for anti- $\beta$-actin; Cell Signaling Technology, Inc., USA) and as a percentage of the control value.

\section{Peritoneal cell and quantitative PCR (qPCR) for IL-1 $\beta$, IL-6 and TNF- $\alpha$}

Peritoneal cells from the control and high-fat animals were isolated as described above. Total RNA was obtained using an RNeasy Mini Kit (Qiagen ${ }^{\circledR}$, USA) according to the manufacturer's protocol. The total RNA was reversetranscribed into cDNA using a High-Capacity cDNA Reverse-Transcription Kit (Applied Biosystems ${ }^{\circledR}$, USA). The cDNA samples were then amplified using TaqMan Universal Master Mix with an optimized concentration of the primer set for IL1 $\beta$ (Mm 00434228_ml, Applied Biosystems, USA), IL-6 (Mm 00446190_ml, Applied Biosystems ${ }^{\circledR}$, USA) and TNF- $\alpha$ (Mm 00443258_ml, Applied Biosystems, USA). The internal control used was ACTB (Mm00607939_s1, Applied Biosystems ${ }^{\circledR}$, USA). The expression of IL1 $\bar{\beta}$, IL- 6 and TNF- $\alpha$ was evaluated by qPCR using StepOnePlus ${ }^{\mathrm{TM}}$ (Applied Biosystems ${ }^{\circledR}$, USA) and quantified by the $\Delta \Delta \mathrm{Ct}$ method.

\section{Statistical analysis}

We performed unpaired Student's t test or MannWhitney test, according to the normality distribution tests, to compare $\mathrm{C}$ or $\mathrm{H}$ groups. To analyze the results from the assays using macrophages and the role of LPS stimulation, One-way ANOVA ${ }^{\circledR}$, or an equivalent non-parametric test (Kruskal-Wallis) were performed. Statistical analyses were performed using GraphPad Prism ${ }^{\circledR} 5.01$ and the level of significance adopted was 0.05 . 


\section{RESULTS}

\section{Feed intake, weight gain, and lipid composition}

As already shown in previous experiments, rodents given a HFD eat less than those fed a control diet (Borges et al., 2013; Santos et al., 2016a). However, weight gain is significant due to the high fat intake in the diet. Based on the Lee index, equivalent to the human body mass index (BMI), there was an increase in visceral fat (periepididymal and retroperitoneal) in HFD-fed animals (Table II).

Adipose tissue (peri-epididymal) from animals fed with a HFD had higher levels of cellular infiltrate between adipocytes, as seen in Figure 1A and 1B. The cellular infiltrate was evaluated by immunohistochemistry, which showed that macrophage infiltration was lower in the $\mathrm{C}$ group (Figure 1C) and higher in the $\mathrm{H}$ group (Figure 1D).

We also performed immunophenotyping of the peritoneal population by flow cytometry, in which we identified that macrophage populations were in similar proportions in the $\mathrm{C}$ (Figure 1E) and $\mathrm{H}$ groups (Figure 1F).

\section{Blood biomarkers}

Leptin, resistin, CRP and cholesterol levels were increased in HFD, as well as HOMA-IR and insulin index, which characterizes greater resistance to insulin. However, there were no differences in the concentrations of glucose, protein and albumin levels (Santos et al., 2016b) between groups. Also, no significant differences were found in scores of erythrocytes, leukocytes, hemoglobin and hematocrit. Bone marrow cellularity is high with slightly diminished peritoneal cellularity (Table III).

\section{Cytokine profiles}

We evaluated TNF- $\alpha$ and IL-1 $\beta$ concentrations in the blood serum of animals and found no detectable production of these cytokines. We detected IL-6 production, but there was no significant difference between groups. We also evaluated these cytokines in culture supernatants of macrophages after 2 hours of cultivation; IL-6 levels were only increased in the LPS-stimulated control group (Figure $2 \mathrm{C}$ ), but there were no differences in the TNF- $\alpha$ (Figure 2A) and IL-1 $\beta$ (Figure 2B) profiles, even among LPS-stimulated cells. Evaluation of the profile of proinflammatory cytokines in peri-epididymal adipose tissue revealed increased production of TNF- $\alpha$ and IL-6 in the LPS-stimulated high-fat group. However, IL-1 $\beta$ did not show significant differences (Figure 3 ).

\section{Determination of NF- $\kappa$ B and phosphorylated NF- $\kappa B$ expression}

The transcription factor NF- $\mathrm{KB}$ showed similar expression values in control and high-fat animals, even when stimulated with LPS. When evaluating phosphorylated NF- $\kappa B$, we also noticed that the control and high-fat animals had similar values; however, high-fat LPS-stimulated cells showed a decrease in phosphorylated $\mathrm{NF}-\kappa \mathrm{B}$ (Figure 4).

\section{IL-1 $\beta$, IL-6 and TNF- $\alpha$ mRNA expression}

HFD resulted in significant increases in TNF- $\alpha$ and IL-6 mRNA expression. However, with regard to both the control and the high-fat group, the values were similar to those of the control group without stimulation (Figure 5).

TABLE II - Diet consumption, lipid and protein intake, body weight variation e lipid profile of the control group and high-fat group of Swiss Webster mice

\begin{tabular}{lcc}
\hline Parameters & $\begin{array}{c}\text { Control } \\
(\mathbf{n}=\mathbf{1 7})\end{array}$ & $\begin{array}{c}\text { High-fat } \\
(\mathbf{n}=\mathbf{1 8})\end{array}$ \\
\hline Diet consumption (g/day) & $7.3 \pm 0.8$ & $4.9 \pm 0.7^{\mathrm{a}}$ \\
Protein consumption (g/day) & $0.9 \mathrm{~g} \pm 0.1$ & $0.8 \mathrm{~g} \pm 0.1$ \\
Lipid consumption (g/day) & $0.6 \pm 0.1$ & $2.1 \pm 0.1^{\mathrm{a}}$ \\
Kcal consumption (day) & $29.2 \pm 2.2$ & $28.5 \pm 3.0$ \\
Body weight variation (\%) & $8.4 \pm 2.6$ & $21.2 \pm 7.6^{\mathrm{a}}$ \\
Epidydimal adipose tissue mass (g) & $2.1 \pm 0.5$ & $2.8 \pm 0.6^{\mathrm{a}}$ \\
Retroperitoneal adipose tissue mass (g) & $0.6 \pm 0.3$ & $0.9 \pm 0.3^{\mathrm{a}}$ \\
Lee index & $3.2 \pm 0.1$ & $3.7 \pm 0.1^{\mathrm{a}}$ \\
\hline
\end{tabular}

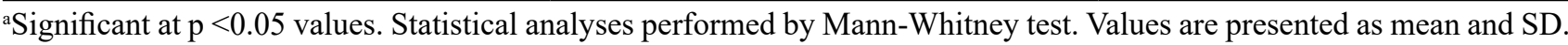



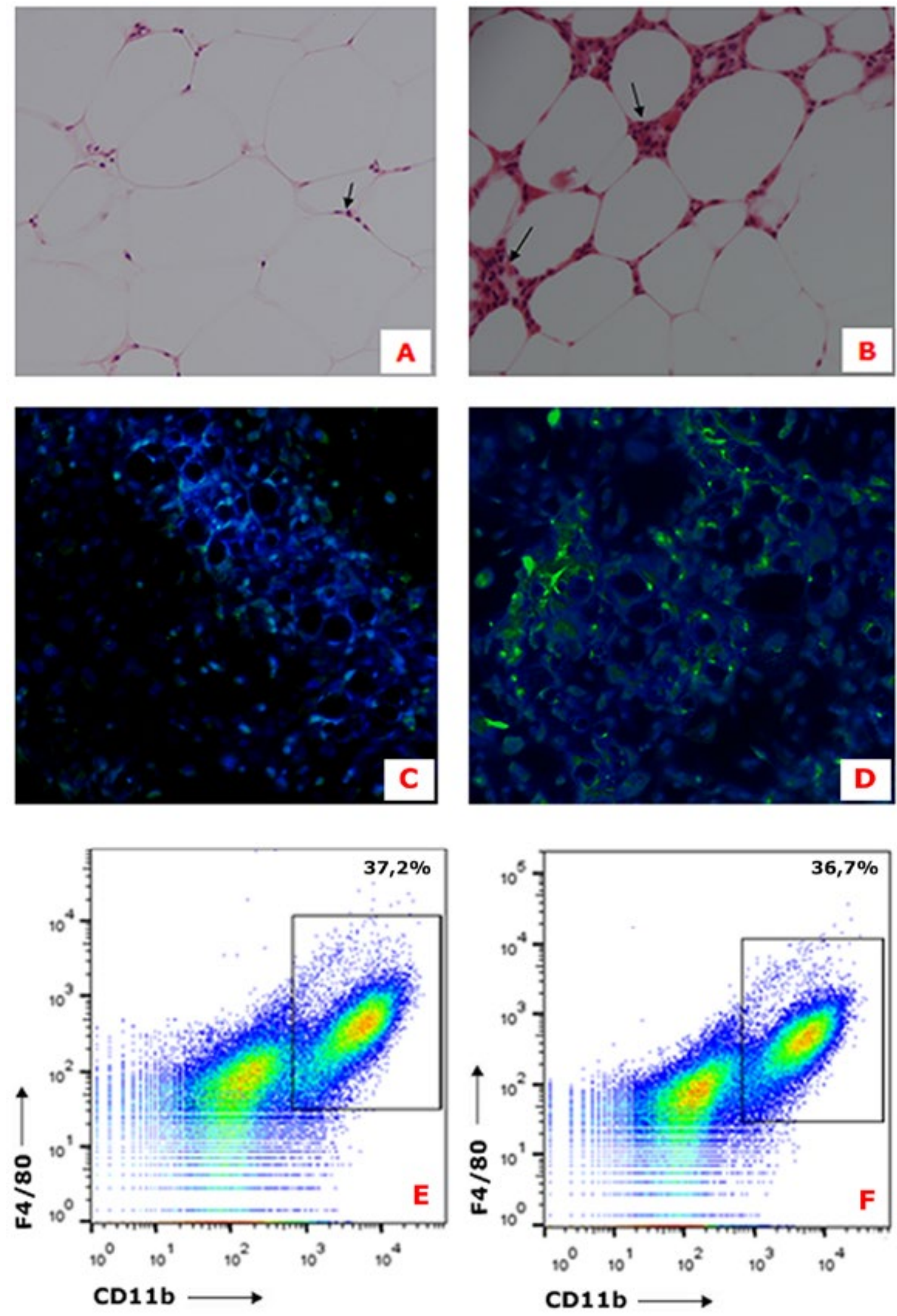

FIGURE 1 - Photomicrograph of representative histological sections of epididymal fat pad stained with hematoxylin-eosin. Control (A) and high-fat (B) animals show cellular infiltrate between the adipocytes, as indicated by the arrows (200x). Immunohistochemistry of adipose tissue showing macrophage infiltrate in Control (C) and High-fat (D). Immunophenotyping of macrophages populations in the peritoneal population by flow cytometry in Control (E) and High-fat (F). 
TABLE III - Inflammatory biomarkers (in blood serum) and blood cell counts of the Control and High-fat groups of Swiss Webster mice

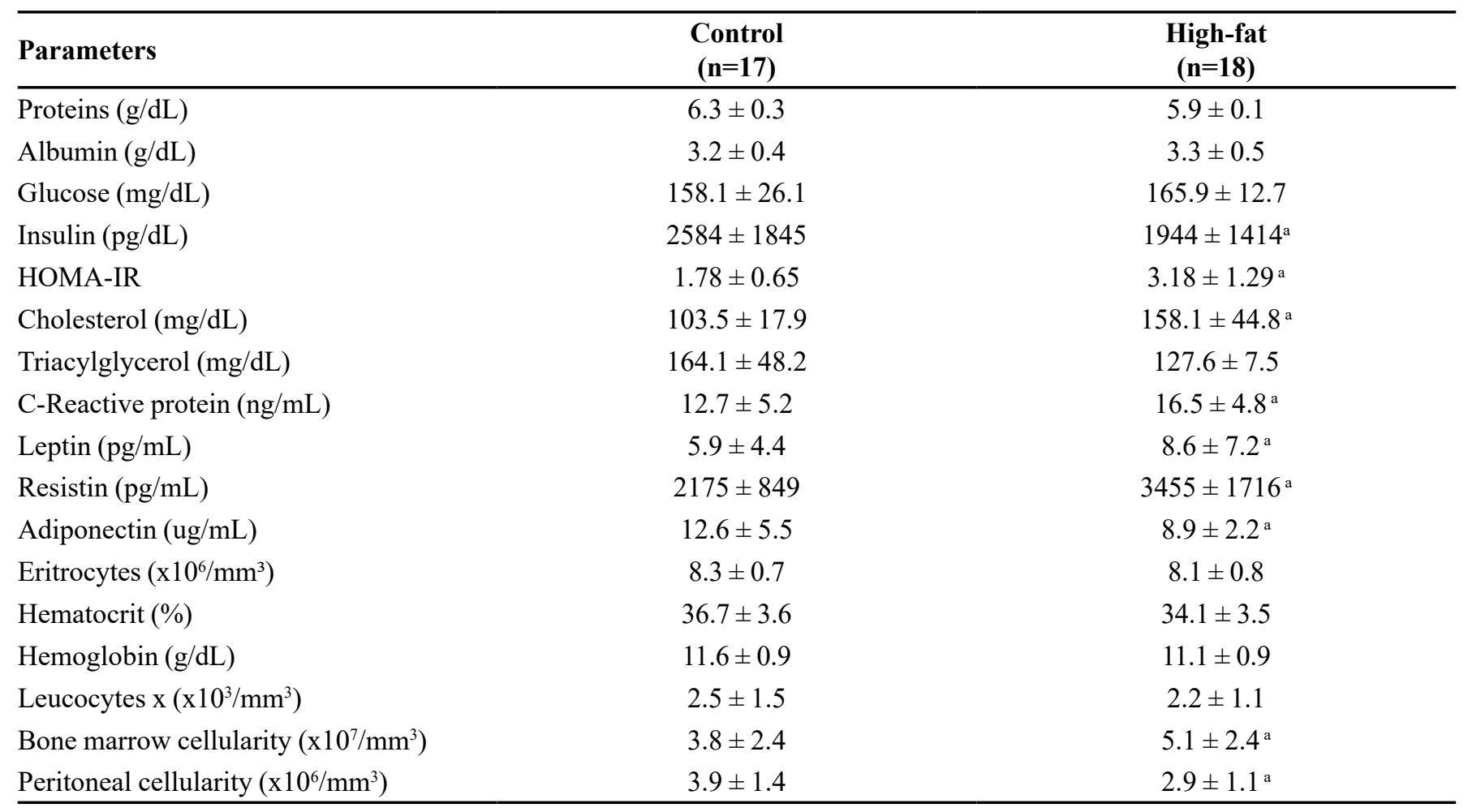

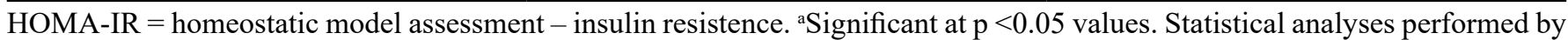
Mann-Whitney test. Values are presented as mean and SD.
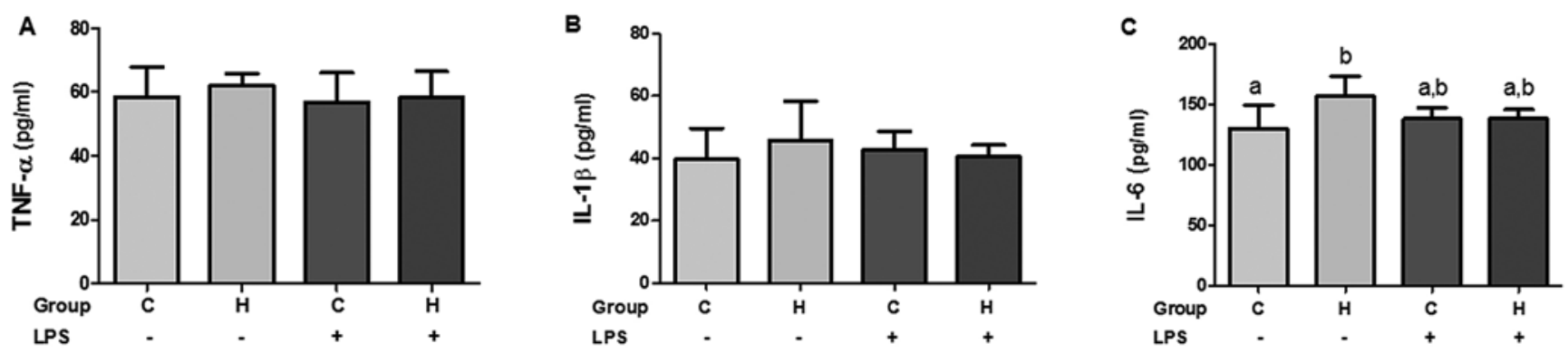

FIGURE 2 - Concentrations of TNF $\alpha$ (A), IL-1b (B) and IL-6 (C) in the culture supernatants of peritoneal macrophages from mice fed with the $\mathrm{C}$ or $\mathrm{H}$ for 6 week and incubated with $(+)$ or not $(-)$ with LPS $(1.25 \mathrm{pg} / \mathrm{mL})$ for $2 \mathrm{~h}$. Values are presented as mean and $\mathrm{SD}(\mathrm{n}=7$ /group). Bars without a common letter differ $(\mathrm{p}<0.05)$. Statistical analysis performed by Kruskal-Wallis test, post hoc Dunns test.

\section{DISCUSSION}

Changes in dietary components can influence important defense mechanisms against pathogens. In this study, we analyzed the effect of a HFD administered for 6 weeks on biochemical parameters related to the lipid profile and macrophage function in a murine model. To induce a state of obesity, we utilized a HFD. The animals in both groups ate similar amounts of calories, protein, and micronutrients, differing only in the proportion of fat ( $30 \%$ of the feed composition in the high-fat group) and carbohydrates.

Although the HFD-fed group ate a smaller amount of feed, animals from both groups ate similar amounts of calories, protein, and micronutrients, differing only in the proportions of fat and carbohydrates. This change in nutrients led to increased adiposity in the animals of the HFD-fed group, evidenced by the increase in visceral fat and by the Lee index (factor that measures the BMI of mice). 

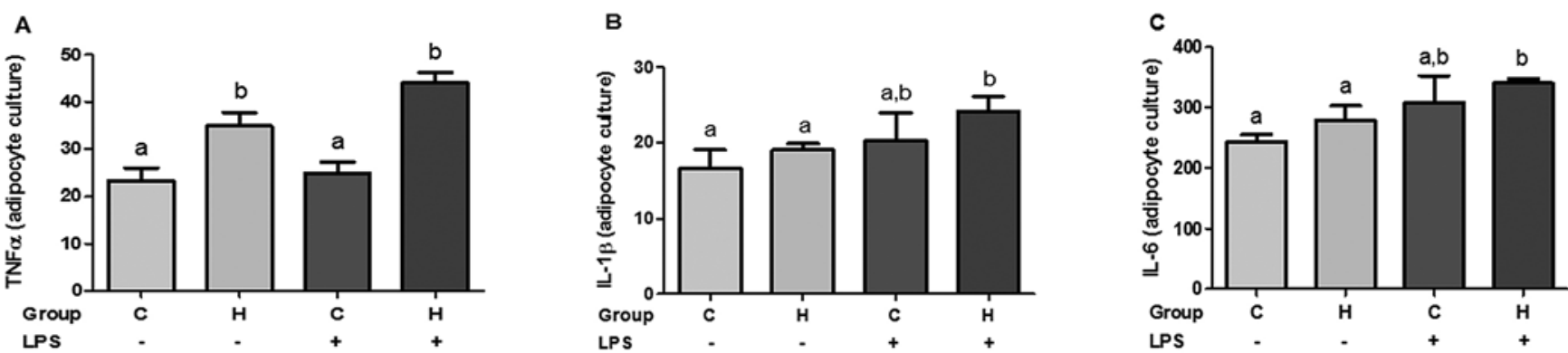

FIGURE 3 - Concentrations of TNF $\alpha$ (A), IL-1b (B) and IL-6 (C) in the adipocyte culture from mice fed with the C or H for 6 week and incubated with (+) or not (-) with LPS $(1.25 \mathrm{pg} / \mathrm{mL})$ for $2 \mathrm{~h}$. Values are presented as mean and SD (n=7/group). Bars without a common letter differ $(\mathrm{p}<0.05)$. Statistical analysis performed by Kruskal-Wallis test, post hoc Dunns test.
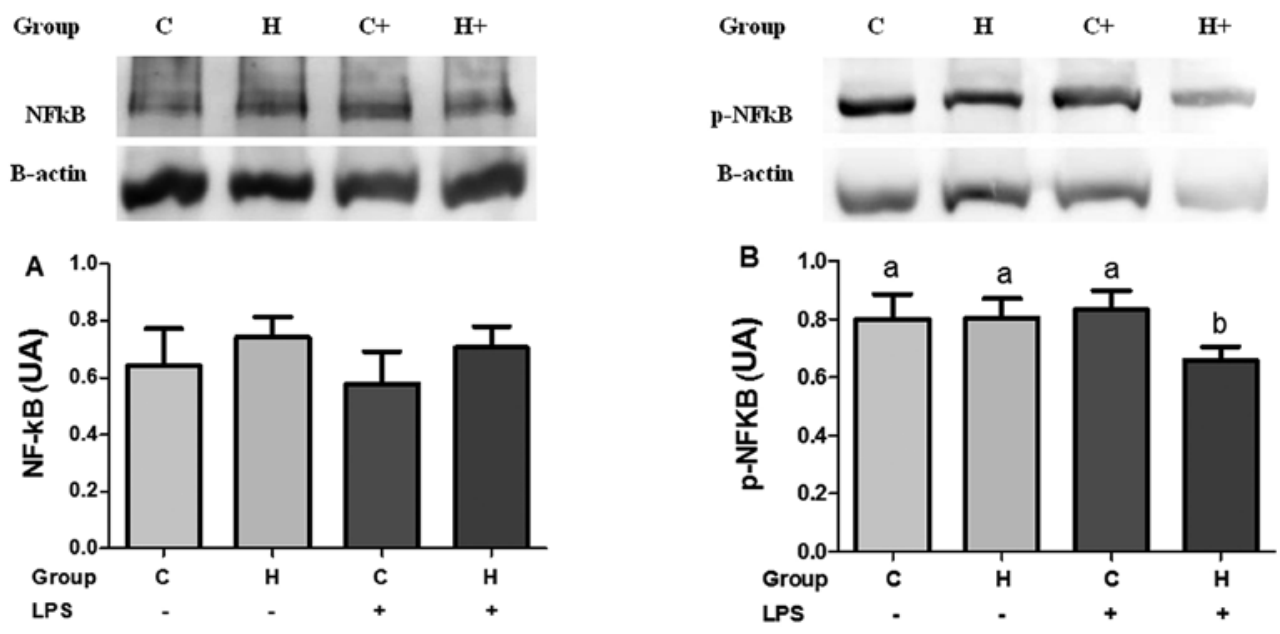

FIGURE 4 - Total (A) and phosphorylated (B) NFkB expression in culture of peritoneal macrophages from mice fed the $\mathrm{C}$ or $\mathrm{H}$ for 6 week and incubated $(+)$ or not (-) with LPS $(1.25 \mathrm{pg} / \mathrm{mL})$ for $2 \mathrm{~h}$. $(\mathrm{n}=6 /$ group$)$.
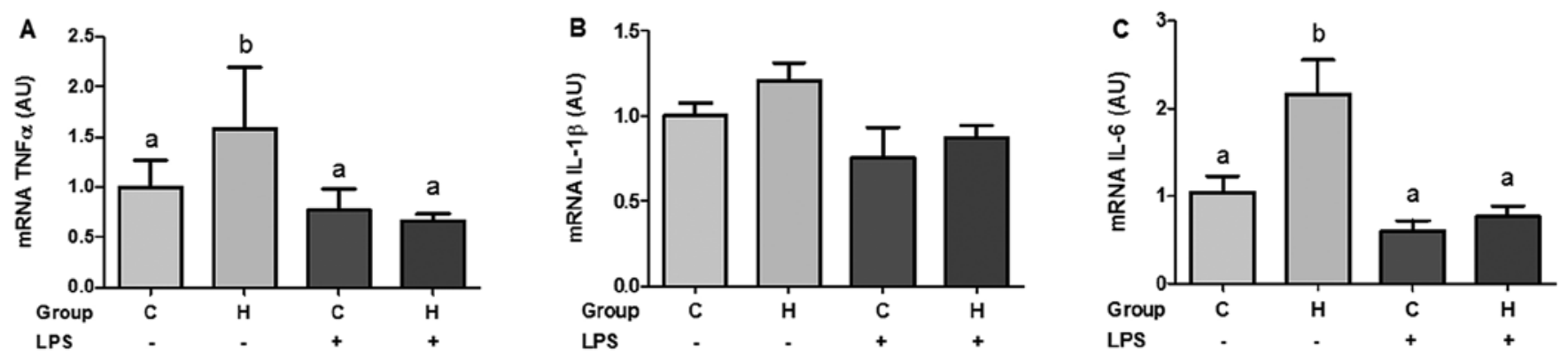

FIGURE 5 - Relative mRNA expressions of TNF $\alpha$ (A), IL-1b (B) and IL-6 (C) of peritoneal macrophages from mice fed the C or $\mathrm{H}$ diet for 6 week and incubated $(+)$ or not $(-)$ with LPS $(1.25 \mathrm{pg} / \mathrm{mL})$ for $2 \mathrm{~h}$. ( $\mathrm{n}=6 /$ group).

Energy accumulation in the form of lipids in the tissues may be the primary factor that contributes to the metabolic syndrome (Figure 6). Adipose tissue is an endocrine organ that secretes substances such as TNF- $\alpha$, IL-6, leptin, and adiponectin. These factors can interfere with food intake and nutrient homeostasis. Obesity disrupts this balance by promoting insulin resistance. The levels of proinflammatory factors, such as TNF- $\alpha$, IL-6 and leptin, are increased, and that of adiponectin, which has anti-inflammatory effects, is reduced (Silveira et al., 2009).

Bone marrow cellularity was increased in the HFDfed group in our study. Leptin also acts on the immune system, stimulating the production of white blood cells in the bone marrow and their migration. The adipose tissue of animals subjected to a HFD showed an increase in the cellular infiltrate between adipocytes, demonstrating an inflammatory process, because these cells increase the 


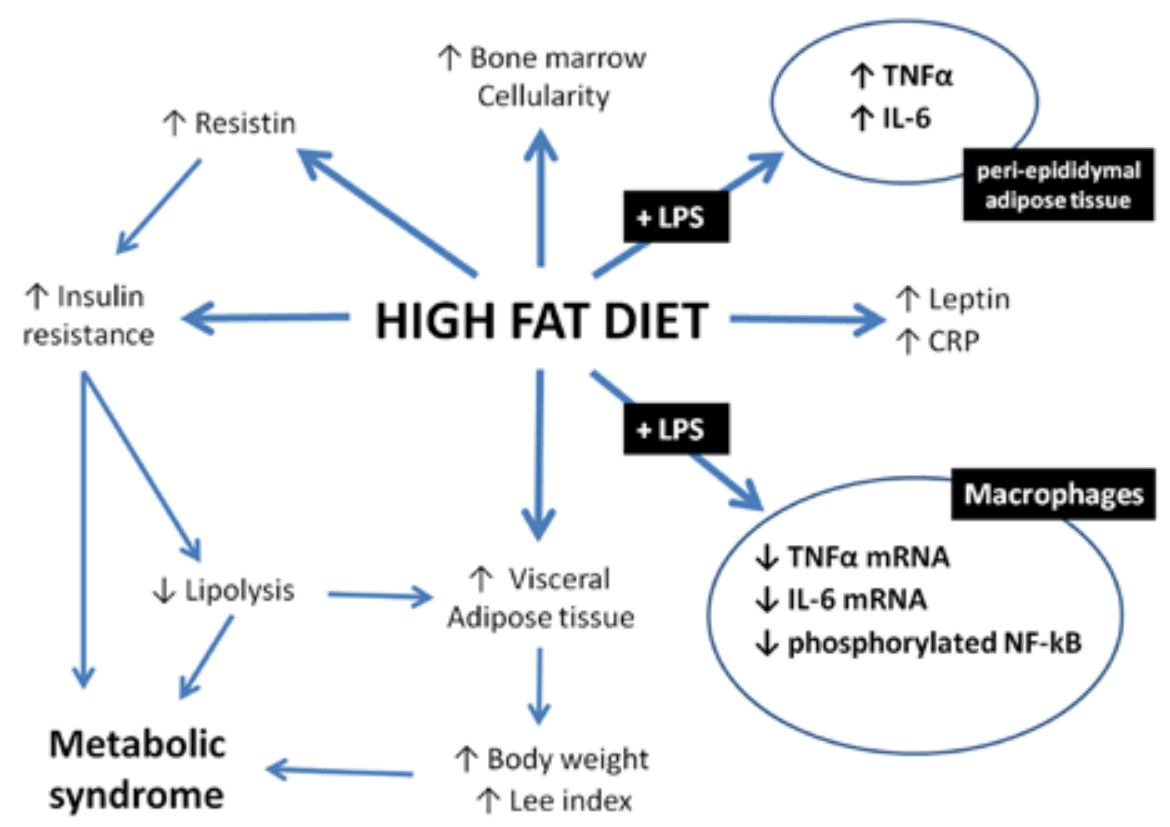

FIGURE 6 - Metabolic disorders associated with high fat diet. The diagram shows the processes affected by high fat diet. Abbreviations: NF-KB, nuclear factor kappa B; TNF, tumor necrosis factor; IL-6, Interleukin-6; LPS, lipopolysaccharide.

expression of proinflammatory mediators such as TNF- $\alpha$ and IL-6 (Lumeng et al., 2007).

HFD-fed mice showed a decreased sensitivity to insulin, demonstrated by the insulin and resistin levels and HOMA-IR index (Koleva, Orbetzova, Atanassova, 2013; Kalupahana et al., 2010), as well as the increased production of CRP, proinflammatory cytokines (IL-6 and TNF- $\alpha$ ), and adipokines (leptin and resistin). CRP levels are increased in response to active infection or acute inflammation (Volp et al., 2008). These changes found in the HFD-fed group, associated with an increased Lee index, body weight, and visceral adiposity, are consistent with the metabolic syndrome observed in humans (Carmo et al., 2013; Bremer, Jialal, 2013; Romeo et al., 2012).

Studies with Wistar rats subjected to a HFD for 12 weeks showed increased concentrations of CRP and leptin (Carmo et al., 2013). However, blood glucose and insulin concentrations and the concentrations of IL- 6 , TNF- $\alpha$, and adiponectin showed no significant differences (Borges et al., 2013; Halaas et al., 1995). However, in our study, mice that underwent 6 weeks of HFD feeding showed decreased insulin levels and increased insulin resistance, although glucose was not altered.

The main effect of insulin on adipose tissue is the reduction of lipolysis, which is the breakdown of lipids and involves the hydrolysis of triglycerides into glycerol and free fatty acids for energy production. This process lowers the level of plasma fatty acids and stimulates the synthesis of fatty acids and triacylglycerols in the tissues, increasing the uptake of triglycerides from the blood to the adipose tissue, which is responsible for the increase in fat deposition in the adipocytes (Dimitriadis et al., 2011).

With the increased fat supply in the body, inflammatory processes are activated, enhancing the production of adipokines such as resistin, which is directly linked to the increase in insulin resistance. In addition, free fatty acids act not only as an energy source but also act as signaling molecules in the modulation of intracellular protein kinases ( $\mathrm{PKC}, \mathrm{JNK}$, etc.), inactivating insulin signaling (Guo, 2014).

TNF- $\alpha$ is a proinflammatory cytokine that can act on neutrophil activation and on the synthesis of acute-phase proteins by stimulating the secretion of chemokines in addition to microbicidal activity, the production of IL$1 \alpha$, and apoptosis (Olefsky, Glass, 2009). In addition, TNF- $\alpha$ promotes the reduction of IRS1 protein levels by the activation of JNK or S6K, resulting in insulin resistance (Guo, 2014). However, the results of high fat diet are controversial: some studies in rats demonstrated an increase in TNF- $\alpha$ production after 12 weeks, while other studies showed no alteration (Borges et al., 2013; Carmo et al., 2013; Cortez et al., 2013; Jacob et al., 2013).

Jellema, Plat and Mensink (2004) suggest a correlation between TNF- $\alpha$ and BMI, in which the reduction of body mass would be linked to a decreased concentration of this cytokine, and it can explain why TNF- $\alpha$ is increased in obese animals (Guimaraes et al., 2007).

In this study, we could not detect serum IL-1 $\beta$. However, when assessing the culture supernatant of 
peritoneal macrophages, we found production but no differences between the groups. We evaluated TNF- $\alpha$ production by adipose tissue and found increased production in vitro. IL-6 is an active cytokine in both natural and acquired immunity. Its production is stimulated by the presence of microorganisms and by IL- $1 \beta$ and TNF- $\alpha$. IL- 6 stimulates the production of acute inflammatory-phase proteins as well as the production of leukocytes, such as neutrophils and B lymphocytes. IL-6 is present in large amounts in adipose tissue and can act as agents of lipolysis as well as inflammation (Tilg, Moschen, 2006).

In evaluating the relative mRNA expression of the proinflammatory cytokines IL- 6 , IL- $1 \beta$, and TNF- $\alpha$, we observed higher expression of the genes encoding these cytokines in HFD-fed animals, whereas both groups of LPS-stimulated animals showed a decrease in the expression of these cytokine genes. Previous work with rats for 12 weeks showed no difference in the expression of the same cytokines between control and HFD-fed groups (Borges et al., 2013).

Activation of the transcription factor NF- $\kappa B$ is critical to the inflammatory response. LPS induces inflammatory genes, including NF- $\kappa \mathrm{B}$ itself, promoting gene transcription and the production of cytokines such as TNF- $\alpha$, IL-1 $\beta$, and IL-6 (Conaway et al., 2017).

It was demonstrated by Fock that NF- $\kappa \mathrm{B}$ activation in control animals is faster than in malnourished ones. The highest level of cytokine transcription by NF- $\mathrm{KB}$ is varied. Meanwhile, TNF levels peak at $60 \mathrm{~min}$ and then decay, and maximum IL- 6 and IL-1a production occur with 2 and 4 hours of stimulation, respectively. Activation of LPS-stimulated NF- $\kappa \mathrm{B}$, therefore, may be rapid or transient (Fock et al., 2007). Diet-induced obesity studies in mice have shown increased activation of NF- $\kappa \mathrm{B}$ (Carlsen et al., 2009), while studies in rats demonstrate impaired activation (Borges et al., 2013). Activation of the NF- $\kappa \mathrm{B}$ transcription factor was assessed by western blotting, where we observed no change in total NF-kB in both groups, even after LPS stimulation. However, we noted that the expression of phosphorylated NF- $\kappa B$ was decreased when the HFD-fed group was stimulated with LPS. This downregulation of the NF- $\mathrm{KB}$ signaling pathway resulting from HFD intake might be related to decreased serine-threonine kinase (Akt) activation and epigenetic changes in NF-kB promoters (Zhou et al., 2011).

\section{CONCLUSION}

In conclusion, the data obtained in this study showed that animals submitted to a HFD for 6 weeks displayed an increase in the Lee index, body weight, and visceral adipose tissue, as well as increased macrophagic activity with a proinflammatory state, characterizing a similar condition to the metabolic syndrome. When stimulated by LPS, the peritoneal macrophages of animals submitted to a HFD exhibit decreased activation of the transcription factor NF-kB. Our study suggests that consumption of a HFD by mice, even in the short term, decreases the ability of peritoneal macrophages to develop an adequate inflammatory response to a bacterial component.

\section{ACKNOWLEDGEMENTS}

Support for this work was provided by the Fundação de Amparo a Pesquisa do Estado de São Paulo (FAPESP 2012/24505-1). E.W.S. was supported by a fellowship from Conselho Nacional de Pesquisa (CNPq 152770/20119). The authors declare that there is no conflict of interest associated with this manuscript.

\section{REFERENCES}

Altintas MM, Rossetti MA, Nayer B, et al. Apoptosis, mastocytosis, and diminished adipocytokine gene expression accompany reduced epididymal fat mass in long-standing dietinduced obese mice. Lipids Health Dis. 2011;10(1):198.

Amar S, Zhou QD, Shaik-Dasthagirisaheb Y, Leeman S. Dietinduced obesity in mice causes changes in immune responses and bone loss manifested by bacterial challenge. Proc Natl Acad Sci USA. 2007;104(51):20466-71.

Borges MC, Vinolo MA, Crisma AR, Fock RA, Borelli P, Tirapegui J, Curi R, Rogero MM. High-fat diet blunts activation of the nuclear factor- $\kappa \mathrm{B}$ signaling pathway in lipopolysaccharide-stimulated peritoneal macrophages of Wistar rats. Nutrition. 2013;29(2):443-9.

Bremer AA, Jialal I. Adipose tissue dysfunction in nascent metabolic syndrome. J Obes. 2013;2013:393192.

Carlsen H, Haugen F, Zadelaar S, Kleemanm R, Kooistra T, Drevon CA, Blomhoff R. Diet-induced obesity increases NF$\kappa B$ signaling in reporter mice. Genes Nutr. 2009;4(3):215-22.

Carswell KA, Lee M-J, Fried SK. Culture of isolated human adipocytes and isolated adipose tissue. Methods Mol Biol. 2012;806:203-214. 
Carmo LS, Rogero MM, Cortez M, Yamada M, Jacob PS, Bastos DHM, Borelli P, et al. The Effects of Yerba Maté (Ilex Paraguariensis) consumption on IL-1, IL-6, TNF- $\alpha$ and IL-10 production by bone marrow cells in wistar rats fed a high-fat diet. Int J Vitam Nutr Res. 2013;83(1):26-35.

Conaway EA, Oliveira DC, McInnis CM, Snapper SB, Horwitz $\mathrm{BH}$. Inhibition of inflammatory gene transcription by IL-10 Is associated with rapid suppression of lipopolysaccharide-induced enhancer activation. J Immun. 2017;198(7):2906-2915.

Cortez M, Carmo LS, Rogero MM, Borelli P, Fock RA. A highfat diet increases IL-1, IL-6, and TNF- $\alpha$ production by increasing $\mathrm{NF}-\kappa \mathrm{B}$ and attenuating PPAR- $\gamma$ expression in bone marrow mesenchymal stem cells. Inflammation. 2013;36(2):379-86.

Dimitriadis G, Mitrou P, Lambadiari V, Maratou E, Raptis SA. Insulin effects in muscle and adipose tissue. Diabetes Res Clin Pract. 2011;93(Suppl 1):S52-9.

FAO, IFAD and WFP. The State of Food Insecurity in the World 2013. The multiple dimensions of food security. Rome, FAO. 2013.

Fock RA, Vinolo MAR, Rocha VMS, Rocha LCS, Borelli P. Protein-energy malnutrition decreases the expression of TLR4/MD-2 and CD14 receptors in peritoneal macrophages and reduces the synthesis of TNF- $\alpha$ in response to lipopolysaccharide (LPS) in mice. Cytokine. 2007;40(2):105-14.

Guimarães DED, Sardinha FLC, Mizurini DM, Carmo MGT. Adipocinas: uma nova visão do tecido adiposo. Rev Nutrição. 2007;20(5):549-59.

Guo S. Insulin signaling, resistance, and the metabolic syndrome: insights from mouse models into disease mechanisms. J Endocrinol. 2014;220(2):T1-T23.

Halaas JL, Gajiwala KS, Maffei M, Cohen SL, Chait BT, Rabinowitz D. Weight-reducing effects of the plasma protein encoded by the obese gene. Science. 1995;269(5223):543-6.

Jacob PS, Fujii TM, Yamada M, Borges MC, Pantaleao LC, Borelli $\mathrm{P}$, et al. Isocaloric intake of a high-fat diet promotes insulin resistance and inflammation in Wistar rats. Cell Biochem Funct. 2013;31(3):244-253.
Jellema A, Plat J, Mensink RP. Weight reduction, but not a moderation intake of fish oil, lower concentrations of inflammatory markers and PAI- 1 antigen in obese men during the fasting and postprandial state. Eur J Clin Invest. 2004;34(11):766-73.

Kalupahana NS, Claycombe K, Newman SJ, Stewart T, Siriwardhana N, Matthan N. Eicosapentaenoic acid prevents and reverses insulin resistance in high-fat diet-induced obese mice via modulation of adipose tissue inflammation. J Nutr. 2010;140(11):1915-22.

Koleva DIV, Orbetzova MM, Atanassova PK. Adipose tissue hormones and appetite and body weight regulators an insulin resistance. Folia Medica. 2013;55(1):25-32.

Lumeng CN, Deyoung SM, Bodzin JL, Saltiel AR. Increased inflammatory properties of adipose tissue macrophages recruited during diet-induced obesity. Diabetes. 2007;56(1)16-23.

Olefsky JM, Glass CK. Macrophages, inflammation and insulin resistance. Annu Rev Physiol. 2009;72:219-46.

Patel PS, Buras ED, Balasubramanyam A. The role of the immune system in obesity and insulin resistance. J Obes. 2013;2013:616193.

Peres CM, Curi R. Obtenção de adipócitos. In: Como cultivar células. Rio de Janeiro: Guanabara-Koogan; 2005; p.83-88.

Reeves PG, Nielsen FH, Fahey GC. AIN-93 purified diets for laboratory rodents final report of the American Institute of Nutrition ad hoc writing committee on the reformulation of AIN-76a rodent diet. J Nutr. 1993;123(11):1939-51.

Rogers P, Webb GP. Estimation of body fat in normal and obese mice. Br J Nutr. 1980;43(1):83-6.

Romeo GR, Lee J, Shoelson SE. Metabolic syndrome, insulin resistance, and roles of inflammation mechanisms and therapeutic targets. Arterioscler Thromb Vasc Bio. 2012;32(8):1771-6.

Saaman MC. The macrophage at the intersection of immunity and metabolism in obesity. Diabetol Metabic Syndr. 2011;3(1):29.

Santos EW, Oliveira DC, Hastreiter AA, Beltran JSO, Rogero MM, Fock RA. High-fat diet or low-protein diet changes peritoneal macrophages function in mice. Nutrire. 2016a;41:1-9. 
Santos EW, Oliveira DC, Hastreiter A, Silva GB, Beltran JSO, Tsujita M, et al. Hematological and biochemical reference values for C57BL/6, Swiss Webster and BALB/c mice. Braz J Vet Res Anim Sci. 2016b;53(2):138-45.

Schaffler A, Scholmerich J, Salzberger B. Adipose tissue as an immunological organ: toll-like receptors, $\mathrm{C} 1 \mathrm{q} / \mathrm{TNF}-\mathrm{s}$ and CTRPs. Trends Immunology. 2007;28(9):393-9.

Silveira MR, Frollini AB, Verlengia R, Cavaglieri CR. Correlação entre obesidade, adipocinas e sistema imunológico. Rev Bras Cineant Desemp Hum. 2009;11(4):466-72.

Tilg H, Moschen AR. Adipocytokines: mediators linking adipose tissue, inflammation and immunity. Nature. 2006;6(10):772-83.

Van Der Heijden RA, Sheedfar F, Morrison MC, et al. High-fat diet induced obesity primes inflammation in adipose tissue prior to liver in C57BL/6j mice. Aging. 2015;7(4):256-8.
Volp ACP, Alfenas RCG, Costa NMB, Minim VPR, Stringueta PC, Bressan J. Capacidade dos biomarcadores inflamatórios em predizer a síndrome metabólica. Arq Bras Endocr Metabol. 2008;52(3):537-49.

Vykhovanets EV, Shankar E, Vykhovanets OV, Shukla S, Gupta $\mathrm{S}$. High-fat diet increases NF- $\mathrm{BB}$ signaling in the prostate of reporter mice. Prostate. 2011;71(2):147-56.

Wellen KE, Hotamisligil GS. Obesity-induced inflammatory changes in adipose tissue. J Clin Invest. 2003;112(12):1785-8.

Zeyda M, Stulnig TM. Adipose tissue macrophages. Immunol Lett. 2007;112(2):61-7.

Zhou QD, Leeman SE, Amar S. Signaling mechanisms in the restoration of impaired immune function due to diet-induced obesity. Proc Natl Acad Sci USA. 2011;108(7):2867-72.

Received for publication on $05^{\text {th }}$ October 2017 Accepted for publication on $16^{\text {th }}$ May 2018 